\title{
El DARDO EN LA METÁFORA
}

\section{Alberto Sánchez Medina ${ }^{1}$}

El académico Fernando Lázaro Carreter llamaba "dardos" a aquellos usos incorrectos del lenguaje, entuertos que el renombrado filólogo trataba de desfacer en su célebre El dardo en la palabra, cuyo éxito propicio la aparición de un segundo volumen de gazapos. Pero, ¿qué pasa cuando la violentada no es una palabra o expresión, sino una metáfora? Si además este mal uso es adrede, y posee el afán de imponer todo un marco cognitivo en el interlocutor, el problema desborda lo lingüístico, y su solución requiere de la comprensión del mecanismo cognitivo que representa la metáfora. Tal es lo que se propone Eduardo de Bustos Guadaño en Metáfora y argumentación: teoría y práctica. Bustos ensalza el valor de la teoría de la mente corpórea de George Lakoff y Mark Johnson, según la cual el proceso cognitivo central de la corporeización de los conceptos abstractos es la metáfora, las cuales dotan de estructura a los conceptos abstractos, dando origen a los procesos inferenciales puestos en juego en el razonamiento y la argumentación. Para el catedrático de Lógica y Filosofía de la Ciencia y profesor de Filosofía del Lenguaje en las Facultades de Filosofía y Filología de la Universidad Nacional de Educación a Distancia (UNED), la metáfora "no sólo estructura nuestro concepto de argumentación, sino que rige la forma en que nos comportamos argumentativamente y la forma en que hablamos de esa actividad central para nuestro concepto de razón". Como se ha dicho, el análisis lingüístico no es suficiente, las metáforas no son hechos lingüísticos aislados, sino la forma en que se manifiesta en lenguaje la topología de nuestros sistemas conceptuales. Estos conceptos se encuentras habitualmente estructurados en diferentes metáforas, que pueden dotar de forma a diversos aspectos de la estructura conceptual, o de diversas formas a un mismo aspecto de esa estructura. Bustos repasa brevemente las cuatro metáforas que se utilizan en la estructuración del concepto de argumentación:

La argumentación es una guerra, que comprende la argumentación a través del concepto de confrontación; los argumentos son edificios

1 Universidad de Salamanca. asmedina@usal.es 
(construcciones), con propiedades tales como el equilibrio o la solidez, o atendiendo a su estética; los argumentos son recipientes, analizada por Michael Reddy y que el autor señala como la metáfora central de nuestra vida mental por la variedad de los campos léxicos que estructura; la argumentación es un viaje, en la que la argumentación se conceptualiza en términos espaciales.

Una argumentación tiene elementos en común con una conversación: unos participantes que asumen los roles de hablante y auditorio intercambian actos verbales comunicativos a través de intervenciones más o menos seriadas. No obstante, lo que hace de una conversación una argumentación es una reconceptualización de los papeles de los participantes, de sus intervenciones y de la trayectoria o estructura lineal de la argumentación verbal, de tal manera que los participantes en el intercambio conciben la argumentación como tal, una polémica que comporta una posición del hablante con respecto del auditorio. Esta posición parte de unas premisas y se orienta a un fin: “Así como todo viaje debe ser llevado a un objetivo, y como todo recipiente está ideado para ser colmado, la argumentación debe tener un objetivo, el establecimiento de una convicción, en una creencia, en la realización de una acción".

“Persuasión era una diosa, un arte de la sofística y una técnica de la retórica. Una divinidad que, según Esquilo, jamás sufrió rechazo. Su signo: la eficacia". Así comienza Persuasión. Estrategias del creer (Universidad el País Vasco), donde el semiólogo y catedrático de Teoría de la Información en la Universidad Complutense de Madrid, desgrana este concepto sin el cual no es posible entender la comunicación, y que para Bustos constituye el punto crucial de la argumentación. Esta eficacia que caracteriza a la persuasión se traduce para Bustos en la activación o inhibición de patrones de activación neuronal, de acuerdo con la reciente teoría neural del lenguaje desarrollada por Feldman y Narayan. Una dimensión pragmática de la argumentación no permite formular ésta como mero conjunto o secuencia de enunciados o proposiciones, sino por conjuntos de acciones lingüísticas realizadas por hablantes de una lengua. Los objetivos que dotan de unidad funcional a las argumentaciones se dividen en aquellos que persiguen la pura manifestación de las opiniones del hablante (exhibitivos) y los que buscan inducir en el auditorio una cierta actitud o la realización de una determinada acción (protrépticos). 
Esto lleva a analizar a Bustos la noción de relevancia, concebida como el conjunto de valores apropiados en una situación comunicativa dada que contribuye a la consecución de los objetivos que persigue la argumentación. El autor entiende este concepto de una manera relacional y dialéctica; la relevancia lo es frente a las acciones de los demás, no es solamente una propiedad interna a las propias. En el contexto de una discusión crítica, la relevancia de una argumentación es relativa a la posición o tesis establecidas y a su tendencia a provocar la aceptación de la posición que el interlocutor quiere mantener. Cuando el hablante introduce su posición a través de metáforas (normalmente en situaciones poco sujetas a convenciones), "es de suma importancia observar que esa maniobra estratégica no solamente implica contenidos estrictamente conceptuales, sino también elementos actitudinales y emocionales que lleva incorporados". Dado que la relevancia atañe a cada una de las fases de la argumentación y a cada una de las partes, el rechazo a una metáfora introducida en el proceso argumentativo también es relevante, y se extiende tanto a su contenido conceptual como a sus posibles componentes cognitivos que lleve aparejados.

En la segunda parte de su estudio, el autor pasa de la teoría a la práctica, analizando cuestiones relativas a la ética de la información, la argumentación de la innovación conceptual a través de la metáfora, el uso de ésta en el discurso político y la relación entre argumentación y terrorismo.

La teoría argumentativa de la ética de la información de Luciano Floridi aspira a convertirse en una macroética no ligada a campos específicos, una ética con principios autónomos respecto a sus aplicaciones específicas. Floridi justifica este desplazamiento desde una consideración epistemológica de la ética de la información hacia una ontologización de la misma por la irrupción de las TIC, pero Bustos duda de la pertinencia de esta especie de "teoría del todo" y se alinea con los críticos de Floridi al considerar por un lado que el nuevo marco ontológico, al que el italiano denomina infosfera, no invalida necesariamente las viejas nociones éticas tradicionales, y que quizás Floridi se confunde al identificar la noción de tener un derecho moral con la de ser objeto de una actitud moral: "Podemos tener actitudes morales, por ejemplo, respecto a un bosque o a una laguna, pero no las convierte ipso facto, en entidades morales ni en titulares de derechos de este tipo". 
La aplicación de la teoría de la metáfora de Bustos define la innovación como un proceso social mediado por mecanismos de valoración crítica y de aceptación razonada en el que los mecanismos de inferencia y argumentación analógica juegan un papel fundamental en la justificación de las innovaciones, que en muchas ocasiones resultan precisamente de la introducción de esas metáforas. Por ejemplo, la elección de Darwin de la metáfora del árbol de la vida en lugar del de coral obedeció a que, aunque ninguno de los dos modelos representase de forma perfecta su pensamiento sobre el origen y la evolución de las especies, el del árbol daba cuenta de algunas relaciones que para él tenían más importancia, de acuerdo con sus objetivos. Darwin prefirió el árbol por ofrecer una representación más estructurada de la evolución de las especies, aunque la metáfora del coral ofreciera una posibilidad que no se daba en aquella: las circunvoluciones coralinas muertas encajaban con los callejones sin salida de las extinciones y con nuestro desconocimiento de ciertos pasos evolutivos en la conformación de las especies. La elección se debe a que la metáfora "ha de satisfacer las expectativas cognitivas de quien las propone o, lo que es lo mismo, ha de permitirle efectuar las inferencias relevantes sobre el dominio objetivo". Otro ejemplo de traducción de la innovación en analogía se dedica a la memética, la cual defiende la analogía entre un meme y un gen. Para los detractores de esta metáfora, el meme falla en su propósito principal de convertirse en un modelo (predictivo, contrastable) de evolución cultural, mientras que sus defensores restan importancia a las carencias de la metáfora y a los fallos en las inferencias analógicas. Estas discrepancias sirven al autor para hacer patentes las diferencias entre creatividad e innovación: mientras que la primera se define contra un marco de conocimiento propios de un paradigma o una comunidad epistémica, la innovación tiene una dimensión social que exige el reconocimiento y la aceptación de diferentes comunidades epistémicas y, en última instancia, del conjunto de la sociedad. Como conclusión, Bustos hace hincapié en la fuerte determinación pragmática del proceso de justificación analógica, y parafrasea la famosa frase de Groucho Marx al decir que las metáforas y las analogías son claras pero que, en ocasiones, los hechos son confusos.

La mencionada teoría de la cognición corpórea permite explicar cómo a partir de la experiencia corporal podemos construir toda clase de conceptos, incluso los más abstractos. Así ocurre en una metáfora 
que identifica la inmigración con un desastre natural: "En los discursos derechistas, pero también en los nacionalistas, la heterogeneidad social y cultural de la inmigración es también fuente de posibles disrupciones de la integridad de la nación, entendida entonces no solamente en puros términos espaciales, sino también sociales y culturales, que se incorporan como una cuarta dimensión a la representación física".

En los dos últimos capítulos, Bustos atiende a lo que para él constituye una dimensión menos explorada y más pertinente para la teoría de la argumentación como es el de la existencia de procesos justificativos del terrorismo suscritos no sólo socialmente sino también por aquellos que cometen las acciones terroristas. El autor muestra la estructura del razonamiento práctico que lleva al terrorista a concebir la acción terrorista como medio necesario desde el punto de vista teórico y coherente desde el punto de vista argumentativo para la consecución de unos determinados fines. Aceptar las premisas que justifican una acción terrorista como condiciones necesarias e incluso suficientes provocan lo que Bandura llama "desconexión moral": si algo se presenta como inevitable se reducen las consecuencias emocionales o morales de aquello que se presenta como medio necesario para conseguir ese fin.

En la película de Hany Abu-Assad Paradise now, que trata sobre la puesta en marcha, justificación y ejecución de un atentado terrorista en Israel por parte de dos gazatíes, una mujer educada en los valores occidentales trata de persuadir a los terroristas, resueltos a inmolarse como condición necesaria para la consecución de sus objetivos políticos, de que existen otras opciones, como la negociación, que son preferibles al terrorismo. Uno de los terroristas acaba por arrepentirse en el último momento e intenta impedir -sin éxito- que su amigo lleve a cabo la acción terrorista. Como explica Bustos, en el discurso terrorista se suelen además de esta presunción de necesidad y suficiencia, la apelación a la urgencia del proceso: el terrorismo es un atajo que desecha todas las opciones que supongan una dilatación del proceso.

El terrorismo, afirma el autor, se ha considerado una respuesta política 'racional' en la medida en que con la inversión de muy escasos recursos (escasos en relación con lo que supone una movilización social tradicional o el reclutamiento de un ejército), puede alcanzar, según el cálculo de sus estrategias, un beneficio máximo. "Las carencias del discurso terroristas 
no son lógicas, sino de juicio. Esto quiere decir que lo que le aqueja es una incapacidad para juzgar (sopesar, ponderar...) tanto sus puntos de vista argumentativos como, sobre todo, para evaluar las consecuencias de sus actos". Por esta razón, el lenguaje terrorista requiere una consideración crítica, basada en la ciencia cognitiva que se centre no solo en el vocabulario o la jerga empleada, sino en el trasfondo cognitivo que da sentido a las formas de hablar del terrorista y de quienes les apoyan, un marco que a menudo es aceptado (quizás de forma inconsciente) haciendo un otorgamiento implícito de razones y de argumentos al terrorista. Bustos pone de relieve la necesidad de implementar programas educativos que integren las herramientas tradicionales para la forja de un espíritu crítico que considere la aceptabilidad del contenido y no sólo de la forma, así como la formación de los servidores públicos al cargo de esa tarea. 